\title{
Who is concerned about and takes action on climate change? Gender and education divides among Thais
}

\author{
Raya Muttarak and Thanyaporn Chankrajang*
}

\begin{abstract}
Using data from Opinions about the Environment and Global Warming 2010, a nationally representative survey of 3900 adults, this study investigates demographic differentials in levels of concern about climate change and climate-relevant behaviours. The factor analysis of 11 environmentally friendly and carbon emissions reduction behaviours identifies two main factors that underlie climate-relevant behaviours: (1) efforts to save electricity and water, and (2) technical and behavioural changes. The multivariate analyses show that women and individuals with higher education are more likely than others to worry a great deal about global warming, and to make technical and behavioural changes. It may be the case that education is positively correlated with making technical and behavioural changes, but not with making efforts to save electricity or water, because the former set of actions require more effort and knowledge to pursue, while the latter set of actions are commonly undertaken for economic reasons. Having concerns about global warming and having experienced environmental problems are also associated with an increased adoption of climate-relevant behaviours.
\end{abstract}

\section{Introduction}

Households are major contributors to the total carbon emissions of a country. For example, the heating of homes in the United States and in most European countries accounts for as much as $30-40 \%$ of total energy consumption (Abrahamse et al.

\footnotetext{
* Raya Muttarak (corresponding author), Wittgenstein Centre for Demography and Global Human Capital (IIASA, VID/ÖAW, WU), International Institute for Applied Systems Analysis (IIASA), Vienna Institute of Demography, Austrian Academy of Sciences, Vienna, Austria

Email: muttarak@iiasa.ac.at

Thanyaporn Chankrajang, Faculty of Economics, Chulalongkorn University, Bangkok, Thailand
} 
2005). Day-to-day activities ranging from burning gas for home heating, using electricity generated from non-renewable resources, and burning gasoline when driving all contribute to greenhouse gas (GHG) emissions. Accordingly, changes in the energy-related behaviours of the public could contribute substantially to the reduction of GHG emissions. As it is generally expected that new low-carbon energy production, energy efficiency, and carbon sequestration technologies will take decades to develop and implement, promoting individual and household behavioural changes appears to be the most feasible option for reducing emissions quickly (Pacala and Socolow 2004).

Although behavioural changes such as adopting existing household technologies or altering modes of personal transportation are fairly straightforward (Gardner and Stern 2008), prompting the public to make voluntary changes in their environmental behaviours may not have the desired result (Dietz et al. 2009). Barriers to the adoption of proactive environmental strategies range from a lack of awareness and understanding, to doubts about the efficacy of one's actions, to a lack of knowledge about how to change one's behaviour to mitigate climate change. Meanwhile, previous studies have demonstrated that informing the public of concerns about climate change can lead people to actively change their climaterelevant behaviours or take political action, as the likelihood of engaging in direct and indirect pro-environmental behaviours has been shown to be positively correlated with awareness of such concerns (Tobler et al. 2012; Wicker and Becken 2013). In particular, when climate risks or impacts are perceived as psychologically close (e.g. geographically or temporally proximate), they can motivate mitigation behaviour (Spence et al. 2012).

Nevertheless, public attitudes regarding climate change and the extent to which people approve of pro-environmental values and behaviours vary considerably by demographic and socio-economic characteristics. Existing studies predominantly carried out in Europe or the United States have found that environmentalism, environmental concerns, and belief in climate change are positively associated with being young, being female, having a left-leaning political ideology, and having relatively high levels of education and income (McCright and Dunlap 2011a; Running 2013; Whitmarsh 2011). Younger people tend to be more environmentally aware than older people, possibly because the younger cohorts are more exposed to media and school curricula that address environmental issues (Howell and Laska 1992). Likewise, the gender gap could be due to different expectations for men and women during parenthood and socialisation processes (Zelezny et al. 2000), gender roles and the division of labour within the family (Blocker and Eckberg 1997), and differences in the value formation processes of men and women (Stern et al. 1995). While boys are raised to be independent and dominant over others, girls are raised to value nature and nurturance. With respect to socio-economic characteristics, highly educated people may know more than those with less education about environmental problems, and about how individuals can change their behaviour and learn more about the environment (Liere and Dunlap 1980; Semenza et al. 2008). Meanwhile, people with relatively high incomes may have been able to fulfil their basic material 
needs, and are therefore looking to achieve a better quality of life and greater environmental sustainability (Inglehart 1995).

Furthermore, not all climate-relevant behaviours require the same amount of effort to implement. Behaviours that contribute to climate change mitigation can be classified as high- or low-cost behaviours. The cost of adopting a certain behaviour includes not just pecuniary costs, but opportunity costs involving time, inconvenience, or the effort needed to pursue the behaviour (Diekmann and Preisendörfer 2003). Typically, the cost of switching from driving a private car to using public transport is high, whereas the cost of recycling or buying eco-friendly products is low. Accordingly, when the cost difference is small, behavioural change is more likely.

Pro-environmental behaviours can also be categorised as efficiency or curtailment behaviours (Gardner and Stern 2002). Efficiency behaviours are one-shot behaviours that involve the purchase of energy-efficient items, such as cars and household appliances. By contrast, curtailment behaviours involve continual efforts to reduce energy consumption by, for example, keeping the thermostat settings low. It therefore appears that technical measures are more accepted than measures designed to change on-going behavioural or consumption patterns (Poortinga et al. 2003). Given the demographic differentials in preferences and opportunities, the adoption of different types of climate-relevant behaviours can vary considerably between population sub-groups.

Meanwhile, previous cross-national studies have shown that public attitudes and perceptions of the threat posed by climate change differ substantially across countries (Lorenzoni and Pidgeon 2006). Risk perception itself is specific to culture and place (Weber and Hsee 1999). Different levels of exposure to climate hazards, as well as social factors such as ethics, norms, and knowledge, may therefore explain this national variation. Likewise, public attitudes about and support for climate change policies can vary considerably between developed and less developed nations. For example, studies have shown that people in developing countries are less likely to express the willingness to pay to combat climate change (Alló and Loureiro 2014). It has been argued that because people in lower income countries are still struggling to meet their basic material needs, they have less room to consider post-materialistic values, such as quality of life, freedom, and the environment (Dunlap and York 2008; Gelissen 2007).

Nevertheless, with the rapid urbanisation and industrialisation of emerging economies, increasing demand for energy use in these countries will have significant effects on their GHG emissions (Sadorsky 2014). While developed countries have to put more effort into emissions reduction, developing countries are also central to climate action, given the substantial growth in their contributions to global carbon dioxide $\left(\mathrm{CO}_{2}\right)$ emissions: the share of global emissions generated by developing countries increased from 33\% in 1990 to $53 \%$ in 2008 (Romani et al. 2012). Understanding the public's level of awareness and perceptions of climate change in these countries could therefore be useful in designing and communicating climate change policies. 
However, most of the studies that focus on perceptions of climate change and pro-environmental behaviours have been carried out in high income countries, while evidence from less developed countries is scarce. Hence, this study aims to provide new empirical evidence on demographic differentials in levels of concern about climate change and in climate-relevant behaviours in Thailand using the 2010 Opinion Survey on Environment and Global Warming (OEGW). The two main research questions investigated in this study are: (1) whether levels of concern about climate change differ according to demographic characteristics; and (2) what the determinants of climate-relevant behaviour are, and whether they vary with different types of behaviours.

As the second-largest economy in Southeast Asia, Thailand is also the secondlargest $\mathrm{CO}_{2}$ emitter in the region (Shrestha and Pradhan 2010). As GDP has risen in Thailand, electricity demand has also increased. Indeed, the demand for electricity from the household sector appears to have risen steadily even after the economic slump in 2008 (APEC 2010). Under the business-as-usual scenario (BAU), Thailand's greenhouse gas emissions are projected to reach 715.2 million tonnes of carbon dioxide equivalent (MtCO2eq) in 2030 and $1398.7 \mathrm{MtCO} e q$ in 2050 (Chotichanathawewong and Thongplew 2012). The latter figure is almost equivalent to the total emissions of India in the year 2008 (IEA 2010). To move towards improving the country's energy security and reducing its GHG emissions, Thailand has adopted the 20-year Energy Efficiency Development Plan 2011-2030 (EEDP). While the plan establishes requirements for energy efficiency via regulations and standards and promotes technology development and innovation, it also includes strategies aimed at fostering public awareness of sustainable energy options and of ways individuals can change their energy consumption behaviour (EEPO 2011). Understanding public perceptions of climate change and individual environmental behaviour is thus essential for the design of effective energy and climate policies.

The remainder of the paper is organised as follows. In the next sections, we describe the survey data and the methods we used for empirical analysis. We then present our results, and discuss our findings in the discussion section. We offer concluding remarks in the final section.

\section{Data}

This study's findings are based on data from Opinions about the Environment and Global Warming (OEGW) 2010, a nationally representative, cross-sectional population-based survey carried out by the National Statistical Office of Thailand (NSO). In order to provide policy-makers with insight into the public's opinions on environmental and global warming-related issues, the survey asked respondents about these topics. Specifically, the survey asked members of the public about the environmental problems they have experienced, their level of concern about global warming and its effects, the activities they have undertaken to reduce global warming, and the strategies they believe are useful for combatting global warming. 
Information on the basic demographic and socio-economic characteristics of the respondents was also collected in the survey.

The OEGW survey was carried out in April 2010 on a nationally representative sample of adults aged $\geq 15$ years in all regions in Thailand. A stratified, three-stage cluster sampling design was adopted, with the strata consisting of five geographic regions: metropolitan Bangkok, north, northeast, central, and south. The primary sampling units (PSUs) were blocks in urban areas or villages in rural areas. In the first stage, the PSUs were randomly selected using selection probability proportional to size sampling, and 390 blocks/villages out of 109,966 blocks/villages in the whole country were selected. In the second stage, ten households were randomly selected from the previously chosen urban or rural PSUs using simple systematic random sampling. In the third stage, one eligible person within each selected household (i.e. a household member aged $\geq 15$ ) was randomly selected for a face-toface interview.

In total, 3900 households were sampled, and 1829 men and 2071 women were interviewed. As there was no missing information in the variables of interest, all 3900 observations were retained for statistical analysis.

While the survey we used is attractive due to its relatively large sample size and wide coverage of the research questions of interest, survey data of this kind can suffer from bias and measurement error. The first problem is social desirability bias: in this case, the respondents' reports of their levels of concern about climate change and of their engagement in mitigation actions may have been overstated. Indeed, some studies purposively designed to test the existence of social desirability bias have found that self-reported data on pro-environmental behaviour in a survey are subject to social desirability biases when tested against observational data (Gamberini et al. 2014). Nevertheless, questionnaires and interviews remain the most widely used methods in pro-environmental and energy conservation studies. Another problem is recall bias in the reporting of the activities undertaken to reduce global warming. The information on climate-relevant behaviours relies solely on self-report methods. The respondents may have recall biases in the retrospective reporting of a one-shot behaviour, such as the purchase of energy-saving light bulbs or energy-efficient appliances. If the action has taken place long ago, the bias may be especially large. Ideally, we would like to have outcome variable measures from different sources (i.e. actual observations of behaviour), but such data are scarcely available. While we acknowledge the potential problems of recall and social desirability biases, it is beyond the scope of this study to address these issues.

\section{Methods}

\subsection{Measures and variables}

\subsubsection{Dependent variables}

This study investigates two outcomes: 


\section{Concern about global warming}

The variable concern about global warming is derived from the following question: 'How much are you worried about the problem of global warming?' The respondents were asked to choose from four possible responses: (1) a great deal, (2) a fair amount, (3) a little, and (4) not at all. Only $4.4 \%$ and $3.2 \%$ of the respondents chose the 'a little' and the 'not at all' categories, respectively. The two categories are thus combined in our statistical analysis.

2. Climate-relevant behaviours

The variable on climate-relevant behaviours is taken from a question that asked the respondents whether they had taken certain actions to minimise the problem of global warming. A list of 11 actions were provided (see Table 1). The respondents were prompted to indicate which actions they had taken and how often they had performed these actions using the following options: (1) regularly, (2) sometimes, and (3) not at all/not applicable. Note that the third category could be problematic since a particular action such as 'setting the air conditioner to $25^{\circ} \mathrm{C}$ ' would not apply to the respondents who did not possess an air conditioner. Accordingly, in the survey those respondents would be classified as having failed to take this action to reduce global warming. This assumption could be misleading, especially when we assess the socio-demographic determinants of climate-relevant behaviours. In the final analysis, such problematic items are excluded.

\subsubsection{Independent variables}

In Table 1 we present a number of other explanatory and control variables added to the analysis, including demographic characteristics, perceptions regarding climate change and environmental issues, and contextual characteristics.

Demographic characteristics Our main goal is to investigate how concerns about global warming and climate-relevant behaviours vary by demographic characteristics, including age, gender, and educational attainment. Age is grouped into six categories: $15-19$ years, $20-29$ years, 30-39 years, 40-49 years, 50-59 years, and $\geq 60$ years. Note that because the survey did not collect age information in exact years, the information on age is available in age groups only. Gender is a dummy variable coded one if the respondent is female, and zero otherwise. Educational attainment is divided into seven levels: no education, primary, lower secondary, upper secondary, vocational, diploma, and bachelor's degree and above.

Empirical support for gender and educational differences in levels of concern about climate change or the environment has been rather consistent. Because of gender differences in socialisation, political orientation, and risk perception, women are generally more likely to believe in global warming and to engage in behaviours that contribute to global warming mitigation (Egan and Mullin 2012; Hamilton and Stampone 2013; Joireman and Liu 2014). The gender socialisation perspective holds 
Table 1:

Overview and descriptive statistics of variables

\begin{tabular}{lcc}
\hline Variable & Scale & \% of respondents \\
\hline Concern about global warming & ordinal & \\
a great deal & & 52.7 \\
a fair amount & 39.9 \\
little/not at all & & 7.4
\end{tabular}

\section{Climate relevant behaviours}

Use cloth bags instead of plastic bags ordinal regularly 11.8

sometimes

never

Plant trees and conserve forests

ordinal regularly

sometimes

never

Use energy-saving light bulbs

regularly

sometimes

Unplug electrical devices when not

ordinal in use

regularly

sometimes

never

Turn off unused lights

80.7

regularly

18.5

sometimes

Use energy-efficient appliances

52.6

regularly

sometimes

10.1

Set air conditioner to $25^{\circ} \mathrm{C}$

ordinal

regularly

11.1

never

Use public transportation rather than a

ordinal private vehicle

regularly

sometimes

never

Turn off the tap while brushing teeth/taking shower

regularly

sometimes

never 
Table 1:

\section{Continued}

\begin{tabular}{|c|c|c|}
\hline Variable & Scale & $\%$ of respondents \\
\hline $\begin{array}{l}\text { Fill a container when washing rather } \\
\text { than running tap water }\end{array}$ & ordinal & \\
\hline regularly & & 58.7 \\
\hline sometimes & & 32.3 \\
\hline never & & 9.0 \\
\hline Reduce the use of styrofoam containers & ordinal & \\
\hline regularly & & 19.7 \\
\hline sometimes & & 56.6 \\
\hline never & & 23.7 \\
\hline Individual characteristics & & \\
\hline female & dummy & 52.7 \\
\hline Age groups & ordinal & \\
\hline aged $15-19$ years & & 7.4 \\
\hline aged $20-29$ years & & 14.5 \\
\hline aged $30-39$ years & & 22.9 \\
\hline aged $40-49$ years & & 22.8 \\
\hline aged $50-59$ years & & 20.6 \\
\hline aged 60 years and over & & 11.8 \\
\hline Highest level of education & ordinal & \\
\hline no education & & 1.9 \\
\hline primary education & & 46.7 \\
\hline lower secondary & & 15.9 \\
\hline upper secondary & & 12.4 \\
\hline vocational & & 4.9 \\
\hline diploma & & 6.1 \\
\hline bachelor's and above & & 12.1 \\
\hline average monthly wage & continuous & $10264(109)^{\mathrm{a}}$ \\
\hline \multicolumn{3}{|l|}{ Climate change perceptions } \\
\hline $\begin{array}{l}\text { Had environmental problems in the } \\
\text { community }\end{array}$ & dummy & 70.4 \\
\hline $\begin{array}{l}\text { Believed that the climate had changed } \\
\text { over the past year }\end{array}$ & dummy & 96.6 \\
\hline $\begin{array}{l}\text { Heard about global warming/climate } \\
\text { change }\end{array}$ & dummy & 95.7 \\
\hline Region of residence & nominal & \\
\hline Bangkok & & 11.4 \\
\hline central region & & 24.0 \\
\hline northern region & & 19.0 \\
\hline north-eastern region & & 33.0 \\
\hline southern region & & 12.7 \\
\hline
\end{tabular}

Note: ${ }^{\mathrm{a}}$ Means and standard errors in parentheses. Sample weight applied for the percentages presented. 
that while boys are socialised to be competitive, independent, and unemotional; girls are socialised to be compassionate, co-operative, and empathetic-characteristics that are associated with caring about nature, including about environmental and climate change concerns (McCright 2010). Furthermore, men tend to feel less vulnerable to risk thanks to their dominant position in the social structure, and are thus more likely than women to seek to manage, control, and benefit from risks. Women, by contrast, are more likely than men to feel vulnerable to risk and to perceive the world as dangerous, as they have less power and control over resources. These gender disparities in perceptions of technological risks also apply to perceptions of climate change risks. With respect to education, we expect to find that education is positively correlated with expressing concerns about global warming and taking climate-relevant actions. Education improves an individual's cognitive ability to evaluate scientific evidence (Egan and Mullin 2012), and increases his or her knowledge of and familiarity with a range of issues, including environmental problems and global warming (Tjernström and Tietenberg 2008). Thus, having more education tends to be associated with increased concern about climate change.

On the other hand, evidence on the effects of age on the level of concern about global warming has been less consistent. Some studies have reported a negative correlation between age and being concerned about global warming (Kellstedt et al. 2008; Malka et al. 2009). With fewer years of remaining life expectancy, older people may believe that global warming is unlikely to affect them personally, and may therefore be less inclined to change their behaviour. However, other studies have found no significant association between age and perceptions of global warming (Wood and Vedlitz 2007).

We also control for income (average monthly wage), as education may capture income differences, and some individuals may be more able than others to afford to engage in certain behaviours. In particular, conserving electricity and water could be motivated by financial incentives, and is directly related to income. However, there is no information on income in the OEGW survey. We therefore impute the income variable by matching each OEGW respondent's reported occupation, sex, and region to the average monthly wage by occupation, sex, and region provided by the quarterly Labour Force Survey (LFS) in 2010 and the Socioeconomic Survey (SES) in 2011. The summary statistics of the average monthly wage, adjusted for the sample weights, is reported in Table 1.

Climate change and environmental perceptions The extent to which a person is concerned about climate change is influenced by his or her perceptions of climate change, which can in turn affect his or her motivation to act (Swim et al. 2009). Furthermore, levels of concern about climate change and climaterelevant behaviours are associated with people's experiences of environmental problems/natural disasters and knowledge of global warming. A number of studies have found that people often conflate climate change with other environmental problems (Reynolds et al. 2010). It is therefore possible that experiencing 
environmental problems increases an individual's willingness to adopt mitigation activities. Similarly, a person's perceptions of having experienced warming or changes in the usual weather patterns have been found to be positively correlated with believing in and being concerned about climate change ( $\mathrm{Li}$ et al. 2011; Taylor et al. 2014). Here we include two dummy variables indicating whether the respondents (1) have experienced an environmental problem in their community, and (2) believe that the weather has changed over the past year.

Region of residence In addition, we control for region of residence, a variable that is divided into five regions: metropolitan Bangkok, central, north, northeast, and south. These five regions differ substantially in terms of social, economic, and geographical characteristics. Bangkok, the capital city, is the largest urban centre in the country. Bangkok's rapid economic development has been accompanied by negative side effects, such as air pollution from intensive traffic, industry, power plants, and incinerators. Moreover, because Bangkok is built on land close to the ocean that is flat, marshy, and unstable, the city is vulnerable to flooding. Meanwhile, the central plain is the most fertile region of the country, but monoculture farming coupled with mismanagement of water irrigation has resulted in land degradation. Low-lying central Thailand is prone to flooding during the rainy season, when rivers tend to swell and overflow. In the mountainous region of northern Thailand, intensive farming with chemicals has led to land degradation. The region has also suffered from deforestation due to illegal logging and improper land use. The northeast has the highest incidence of poverty and the greatest number of poor residents. As this region consists primarily of a semi-arid plateau with sandy infertile soil, its main agricultural products are rainfed rice and low-return dryland field crops such as cassava. Poor soil conditions coupled with an uneven distribution of rainfall and limited irrigation facilities make the northeast particularly prone to drought. The south, on the other hand, is one of the wealthiest regions thanks to its rubber plantations and fruit production, as well as the fishing and international tourism industries in its coastal areas (McGregor 2008). However, growth in tourism, fisheries, port development, and shrimp farming in the region have led to mangrove destruction, salinisation, and coastal erosion. Climate change is likely to exacerbate these existing environmental challenges, and these regional differences may influence the respondents' climate change attitudes and behaviours accordingly.

\subsubsection{Statistical analysis}

The data analysis consists of three main steps. First, in order to address the first research question on demographic differentials in concerns about climate change, the variable that measures the level of 'worry about the problem of global warming' was recoded into three categories in a sequential order: (1) little/not at all, (2) a fair amount, and (3) a great deal. Because the outcome variable was not normally 
distributed, ordinary least squares (OLS) regression could not be used, as the normality assumption would be violated. Thus, ordered logistic regression, as outlined below, is employed to estimate the association between concern about climate change and demographic characteristics given the ordinal response variable like ours.

$$
\begin{aligned}
& y_{i}^{*}=\beta_{0}+\beta_{1} \text { female }_{i}+\beta_{2} \text { age }_{i}+\beta_{3} \text { education }_{i}+\beta_{4} \boldsymbol{x}_{i}+\varepsilon_{i}, \\
& y_{i}=1 \text { if } y_{i}^{*} \leq \gamma_{1} \\
& y_{i}=2 \text { if } \gamma_{1}<y_{i}^{*} \leq \gamma_{2} \\
& y_{i}=3 \text { if } y_{i}^{*}>\gamma_{2} \text {, }
\end{aligned}
$$

where $y_{i}^{*}$ is the underlying latent concern about climate change of an individual $i$, which is modelled as a function of demographic variables female f $_{i}$ age $_{i}$, education $_{i}$, and other controlled characteristics $\boldsymbol{x}_{i}$ such as environmental perceptions and region of residence. If $y_{i}^{*}$ is smaller than or equal to the unknown parameter $\gamma_{1}$, the individual $i$ will report that he or she is a little or not at all concerned about the problem of global warming. If $\gamma_{1}<y_{i}^{*} \leq \gamma_{2}$, the individual $i$ will report that he or she has a fair amount of concern. If $y_{i}^{*}>\gamma_{2}$, the individual $i$ will report that he or she has a great deal of concern. Both $\gamma_{1}$ and $\gamma_{2}$ are estimated jointly with $\beta_{i}$ in the model.

In addition, the likelihood-ratio test was performed to test the proportional odds assumption, and the results confirmed that the assumption was not violated (Wolfe and Gould 1998). Hence, the use of ordered logistic estimation is justified.

Second, exploratory factor analysis was performed to identify the number of behavioural dimensions and to cluster the items that measured the same climaterelevant behaviours. The 11 items of the behaviours listed in Table 1 were subjected to a principal components analysis. The item 'set air conditioner to $25^{\circ} \mathrm{C}$ ' has a rather high uniqueness value of 0.52 ; i.e. $52 \%$ of the common variance of the variable not associated with the factors. Thus, the item is excluded from the final factor analysis. In addition, since a response to the item 'use public transportation rather than private vehicle' depends considerably on whether the respondent possesses a private vehicle, this item was also excluded. Factor analysis was then performed on nine items.

The factor analysis for the items that capture climate-relevant behaviours resulted in a two-factor solution, as presented in Table 2. For both of the factors retained, all of the items have factor loadings of $>.40$, except for 'planting trees and forest conservation', which has factor loadings of .37. The first factor labelled 'electricity and water saving' explained $55.3 \%$ of the variance, and consisted of four items: two actions that contribute to saving electricity (i.e. unplugging electrical devices when not in use and turning off unused lights), and two actions that contribute to saving water (i.e. turning off the tap while brushing teeth/taking a shower and filling a container when washing rather than running tap water). The index of electricity and water saving was constructed based on these four items (Cronbach's $\alpha=0.64$ ). The second factor labelled 'technical and behavioural change' explained $44.7 \%$ of the 


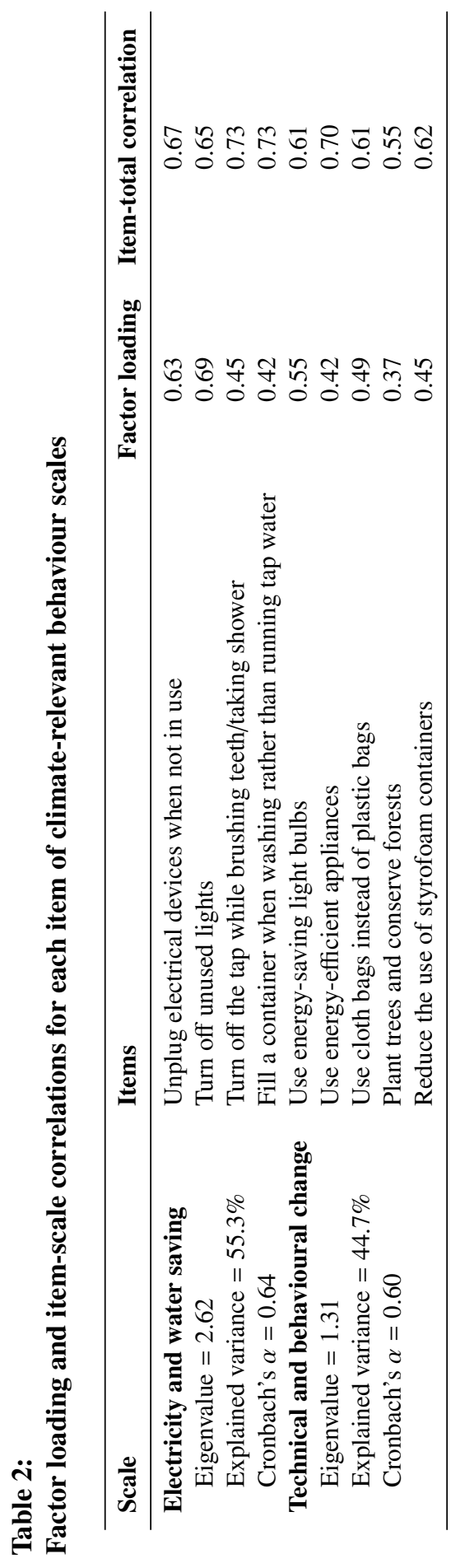


variance, and consisted of five items: two items that represent efficiency behaviours (i.e. using energy-saving light bulbs and using energy-efficient electrical devices), and three items that represent curtailment behaviours involving repetitive efforts to reduce GHG emissions (i.e. using a cloth bag instead of a plastic bag, planting trees and conserving forests, and reducing the use of styrofoam containers). The index of technical and behavioural change was constructed based on these five items (Cronbach's $\alpha=0.60$ ).

Third, to answer the second research question on the determinants of climaterelevant behaviours and how these determinants vary with different behaviours, OLS regressions on the two behaviour indices (i.e. electricity and water saving and technical and behaviour changes) created from factor analysis were performed. OLS regression is an appropriate method since the two indices are normally distributed. Each index has a maximum score of three. The higher the score, the more engaged the respondent is in climate-friendly behaviours.

\section{Results}

\subsection{Demographic differentials in concern about global warming}

Table 3 presents a series of ordered logit models that estimate the level of concern about global warming, while taking into account demographic characteristics and other relevant factors. The first model considers demographic characteristics only, while the second model controls for perceptions about climate change and the environment. The last model includes a control for region of residence, as location may influence the level of concern about global warming.

Across the three models, we observe significant gender and educational differentials in levels of concern about global warming. The odds of having a great deal of concern about global warming are 1.2 times $\left(e^{0.148}\right)$ higher for women than for men. The association between educational attainment and the level of concern about global warming is rather linear. Compared to those with no education, the respondents with an upper secondary level of education or higher were significantly more likely to report that they are worried about global warming. In particular, respondents with a bachelor's degree were 2.9 times $\left(e^{1.076}\right)$ more likely to say they are concerned about global warming. No significant relationship is observed between age or income, as estimated by $\log$ (monthly wage), and level of concern about global warming. Individuals who reported living in a community with environmental problems expressed higher levels of concern about global warming. Meanwhile, respondents who said they believe the weather had changed over the past year were 2.3 times $\left(e^{0.831}\right)$ more likely to express concern about global warming. Compared to the central region, respondents living in the south expressed significantly lower levels of concern. 
Table 3:

Ordered logit estimates of concern about global warming

\begin{tabular}{|c|c|c|c|c|c|c|}
\hline & \multirow{2}{*}{\multicolumn{2}{|c|}{$\begin{array}{c}\text { Model 1 } \\
\begin{array}{c}\text { Demographic } \\
\text { characteristics }\end{array}\end{array}$}} & \multirow{2}{*}{\multicolumn{2}{|c|}{$\frac{\text { Model } 2}{\begin{array}{c}\text { Climate change } \\
\text { perceptions }\end{array}}$}} & \multirow{2}{*}{\multicolumn{2}{|c|}{$\begin{array}{c}\text { Model 3 } \\
\begin{array}{c}\text { Other } \\
\text { characteristics }\end{array}\end{array}$}} \\
\hline & & & & & & \\
\hline & $\beta$ & s.e. & $\beta$ & s.e. & $\beta$ & s.e. \\
\hline \multicolumn{7}{|l|}{ Demographic characteristics } \\
\hline female & $0.129^{*}$ & $(0.065)$ & $0.148 *$ & $(0.067)$ & $0.148 *$ & $(0.067)$ \\
\hline aged $15-19$ years & ref & & ref & & ref & \\
\hline aged $20-29$ years & 0.066 & $(0.176)$ & 0.055 & $(0.175)$ & 0.054 & $(0.176)$ \\
\hline aged $30-39$ years & 0.001 & $(0.160)$ & 0.008 & $(0.159)$ & 0.000 & $(0.160)$ \\
\hline aged $40-49$ years & 0.077 & $(0.160)$ & 0.079 & $(0.155)$ & 0.070 & $(0.156)$ \\
\hline aged $50-59$ years & -0.064 & $(0.182)$ & -0.063 & $(0.177)$ & -0.073 & $(0.178)$ \\
\hline aged 60 years and over & 0.109 & $(0.203)$ & 0.151 & $(0.199)$ & 0.145 & $(0.198)$ \\
\hline no education & ref & & ref & & ref & \\
\hline primary education & 0.412 & $(0.270)$ & 0.402 & $(0.274)$ & 0.381 & $(0.271)$ \\
\hline lower secondary & 0.480 & $(0.295)$ & $0.501+$ & $(0.294)$ & $0.482+$ & $(0.291)$ \\
\hline upper secondary & $0.811 * *$ & $(0.300)$ & $0.830 * *$ & $(0.297)$ & $0.816^{* *}$ & $(0.296)$ \\
\hline vocational & $0.595^{*}$ & $(0.290)$ & $0.686^{*}$ & $(0.287)$ & $0.657 *$ & $(0.287)$ \\
\hline diploma & $0.921 * *$ & $(0.284)$ & $0.974 * * *$ & $(0.283)$ & $0.962 * * *$ & $(0.281)$ \\
\hline bachelor and above & $1.047 * * *$ & $(0.291)$ & $1.085^{* * *}$ & $(0.287)$ & $1.076^{* * *}$ & $(0.287)$ \\
\hline $\log ($ wage $)$ & 0.000 & $(0.007)$ & 0.002 & $(0.007)$ & 0.001 & $(0.007)$ \\
\hline \multicolumn{7}{|l|}{ Climate change perceptions } \\
\hline \multicolumn{7}{|l|}{ Had environmental problems } \\
\hline in the community & & & $0.624 * * *$ & $(0.128)$ & $0.632 * * *$ & $(0.129)$ \\
\hline \multicolumn{7}{|l|}{ Believed that the climate } \\
\hline had changed over the past year & & & $0.838 * * *$ & $(0.207)$ & $0.831 * * *$ & $(0.194)$ \\
\hline \multicolumn{7}{|l|}{ Region of residence } \\
\hline central region & & & & & ref & \\
\hline Bangkok & & & & & -0.148 & $(0.183)$ \\
\hline northern region & & & & & -0.151 & $(0.170)$ \\
\hline north-eastern region & & & & & -0.149 & $(0.202)$ \\
\hline southern region & & & & & $-0.364^{*}$ & $(0.167)$ \\
\hline Little versus a fair amount/great deal & $-1.878^{* * *}$ & $(0.328)$ & $-0.636+$ & $(0.344)$ & $-0.809^{*}$ & $(0.353)$ \\
\hline Little/a fair amount versus great deal & $0.568+$ & $(0.313)$ & $1.861 * * *$ & $(0.329)$ & $1.692 * * *$ & $(0.333)$ \\
\hline Observations & 3,900 & & 3,900 & & 3,900 & \\
\hline Population size & 779.999 & & 779.999 & & 779.999 & \\
\hline Number of strata & 5 & & 5 & & 5 & \\
\hline Number of PSUs & 193 & & 193 & & 193 & \\
\hline
\end{tabular}

Note: Standard errors in parentheses. Sample weight applied for the analysis presented.

${ }^{* * *} p<0.001,{ }^{* *} p<0.01,{ }^{*} p<0.05,+p<0.1$. 
Table 4:

Percentages distribution of climate-relevant behaviours by gender

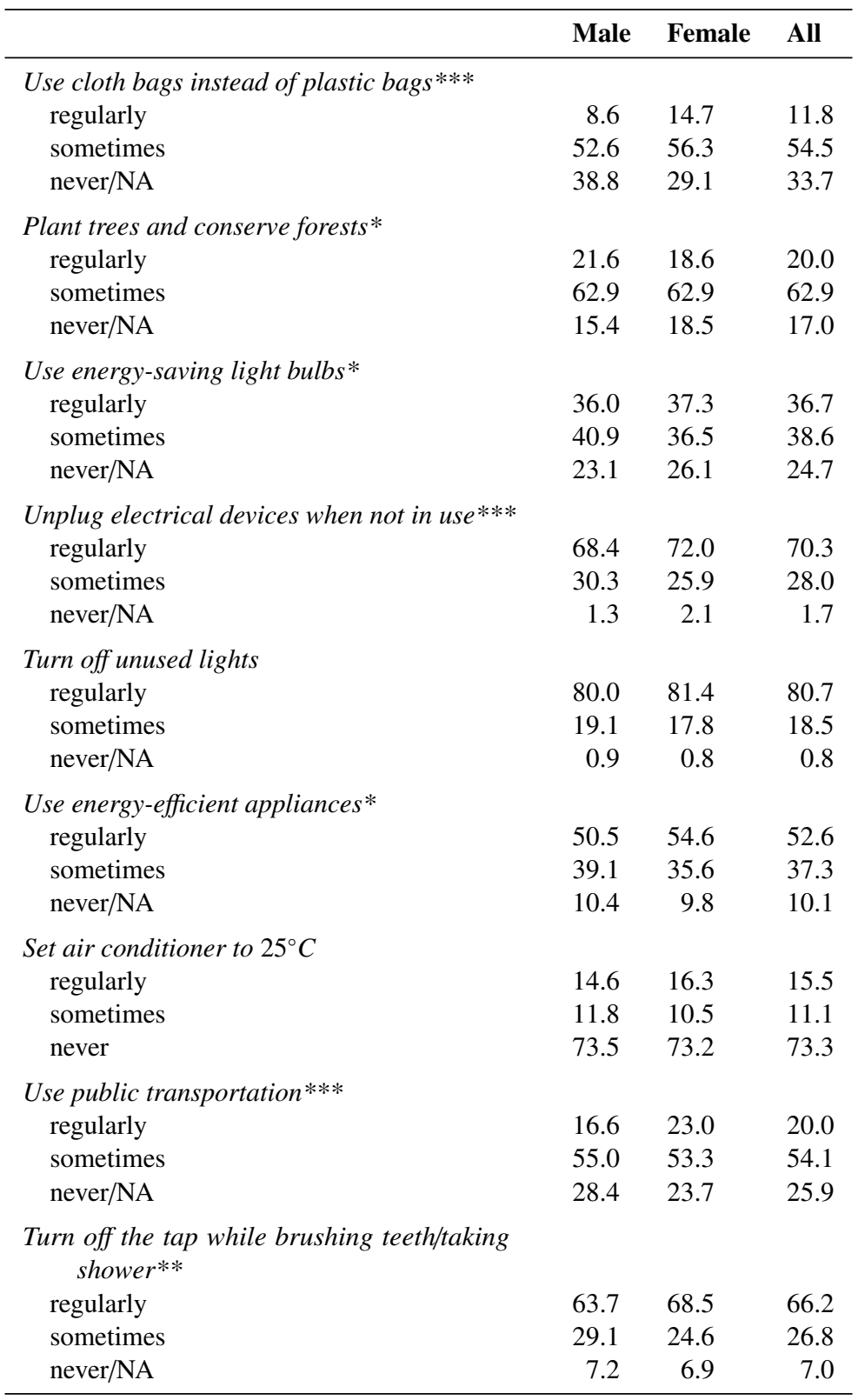

Continued 
Table 4:

Continued

\begin{tabular}{lrrr}
\hline & Male & Female & All \\
\hline $\begin{array}{l}\text { Fill a container when washing rather than } \\
\quad \text { running tap water }\end{array}$ & & & \\
$\quad$ regularly & 57.6 & 59.7 & 58.7 \\
$\quad$ sometimes & 32.6 & 32.1 & 32.3 \\
$\quad$ never/NA & 9.8 & 8.2 & 9.0 \\
Reduce the use of styrofoam containers* & & & \\
$\quad$ regularly & 18.6 & 20.7 & 19.7 \\
$\quad$ sometimes & 55.9 & 57.3 & 56.6 \\
$\quad$ never/NA & 25.6 & 21.9 & 23.7 \\
\hline
\end{tabular}

Note: ${ }^{* * *} p<0.001,{ }^{* *} p<0.01,{ }^{*} p<0.05$

Sample weight applied for the percentages presented. P-value is obtained from a chi-square test of association between gender and each behaviour.

\subsection{Demographic differentials in climate relevant behaviours}

Table 4 presents the distribution of 11 items related to climate-relevant behaviours by gender. Chi-square tests were performed to test the relationship between gender and each climate action. For most actions, the proportion of individuals who regularly engaged in environmentally friendly behaviours was significantly greater for women than for men. The four actions that were most commonly carried out regularly by both men and women were related to electricity and water conservation: i.e. turning off unused lights $(80.7 \%)$, unplugging electrical devices when not in use (70.3\%), turning off the tap while brushing teeth/taking a shower $(66.2 \%)$, and filling a container rather than running tap water $(58.7 \%)$. The majority of the respondents reported using energy-efficient appliances (52.6\%), while about one-third said they use energy-saving light bulbs. Only about one-fifth of the respondents said they had taken actions that involve consistent efforts to change their behaviours and are associated with some degree of inconvenience, such as using public transportation, planting trees, and setting the air conditioner to $25^{\circ} \mathrm{C}$.

The factor analysis (see Table 2) reveals that climate-relevant behaviours can be grouped into two types of actions: (1) electricity and water saving measures; and (2) technical and behavioural changes. Table 5 displays OLS regression estimates for the two climate-relevant behaviours based on demographic and contextual characteristics and on climate change and environmental perceptions.

Women were more engaged in both climate-relevant behaviours than men. With respect to age, the older age groups were significantly more engaged in electricity and water saving actions than the respondents aged 15-19. However, we observe no age gradient in the likelihood of undertaking technical and behavioural changes. While education was not significantly associated with electricity and water saving, it had a positive relationship with technical and behavioural changes. 
Table 5:

OLS regression analysis for climate-relevant behaviours

\begin{tabular}{|c|c|c|c|c|}
\hline & \multicolumn{2}{|c|}{$\begin{array}{l}\text { Electric and } \\
\text { water saving }\end{array}$} & \multicolumn{2}{|c|}{$\begin{array}{l}\text { Technical and } \\
\text { behavioural change }\end{array}$} \\
\hline & $\beta$ & s.e. & $\beta$ & s.e. \\
\hline \multicolumn{5}{|l|}{ Demographic characteristics } \\
\hline female & $0.036 * *$ & $(0.011)$ & $0.040 * * *$ & $(0.012)$ \\
\hline aged $15-19$ years & ref & & ref & \\
\hline aged $20-29$ years & 0.032 & $(0.030)$ & -0.047 & $(0.029)$ \\
\hline aged $30-39$ years & $0.103 * *$ & $(0.031)$ & -0.023 & $(0.030)$ \\
\hline aged $40-49$ years & $0.097 * *$ & $(0.032)$ & 0.033 & $(0.030)$ \\
\hline aged $50-59$ years & $0.131 * * *$ & $(0.034)$ & 0.022 & $(0.030)$ \\
\hline aged 60 years and over & $0.117 * *$ & $(0.039)$ & 0.004 & $(0.039)$ \\
\hline no education & ref & & ref & \\
\hline primary education & 0.058 & $(0.057)$ & $0.156 * * *$ & $(0.045)$ \\
\hline lower secondary & 0.058 & $(0.060)$ & $0.234 * * *$ & $(0.050)$ \\
\hline upper secondary & 0.061 & $(0.064)$ & $0.302 * * *$ & $(0.048)$ \\
\hline vocational & 0.095 & $(0.070)$ & $0.317 * * *$ & $(0.051)$ \\
\hline diploma & 0.040 & $(0.068)$ & $0.353 * * *$ & $(0.055)$ \\
\hline bachelor and above & 0.077 & $(0.065)$ & $0.430 * * *$ & $(0.051)$ \\
\hline $\log ($ wage $)$ & -0.001 & $(0.001)$ & -0.001 & $(0.001)$ \\
\hline \multicolumn{5}{|l|}{ Climate change perceptions } \\
\hline Worry a little/not at all about global warming & ref & & ref & \\
\hline Worry a fair amount about global warming & 0.023 & $(0.046)$ & $0.104 * *$ & $(0.036)$ \\
\hline Worry a great deal about global warming & $0.095^{*}$ & $(0.045)$ & $0.175 * * *$ & $(0.037)$ \\
\hline Had environmental problems in the community & 0.053 & $(0.032)$ & $0.073 * *$ & $(0.027)$ \\
\hline $\begin{array}{l}\text { Believed that the climate had changed over the } \\
\text { past year }\end{array}$ & 0.040 & $(0.048)$ & 0.051 & $(0.051)$ \\
\hline \multicolumn{5}{|l|}{ Region of residence } \\
\hline central region & ref & & ref & \\
\hline Bangkok & -0.023 & $(0.038)$ & 0.011 & $(0.036)$ \\
\hline northern region & -0.012 & $(0.046)$ & -0.029 & $(0.042)$ \\
\hline north-eastern region & -0.003 & $(0.043)$ & $-0.158 * * *$ & $(0.036)$ \\
\hline southern region & -0.040 & $(0.044)$ & -0.008 & $(0.036)$ \\
\hline constant & $2.356 * * *$ & $(0.097)$ & $1.632 * * *$ & $(0.076)$ \\
\hline Observations & 3,900 & & 3,900 & \\
\hline Population size & 779.999 & & 779.999 & \\
\hline Number of strata & 5 & & 5 & \\
\hline Number of PSUs & 193 & & 193 & \\
\hline R-squared & 0.030 & & 0.122 & \\
\hline
\end{tabular}


Figure 1:

Predicted score with $95 \%$ confidence interval of adopting electricity and water saving behaviour for a person aged 40-49 years living in the south

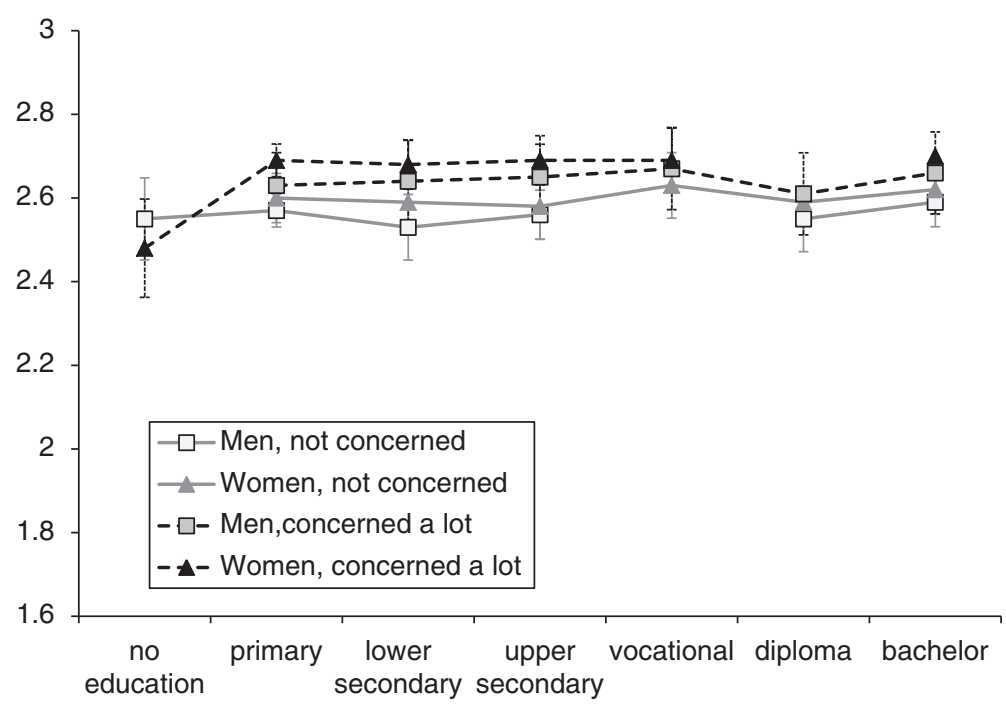

Income had no significant relationship with either group of behaviours. Concern about global warming was positively related with engagement in climate-relevant behaviours, especially technical and behavioural changes. In addition, respondents who were living in the northeast were less likely to report engaging in technical and behavioural changes than those who were living in the central region.

In order to visualise the relationship between education and the uptake of climate-relevant behaviours, we calculated the predicted scores of climate-relevant behaviours for a hypothetical person aged 40-49 who was living in the south, based on the OLS estimates in Table 5. Figures 1 and 2 illustrate the likelihood of adopting electricity and water saving behaviours and of undertaking technical and behavioural changes by gender, education, and level of concern about global warming. Figure 1 shows that the likelihood of adopting electricity and water saving behaviours varies little by gender, education, or level of concern about global warming. On the other hand, Figure 2 shows that the likelihood of adopting technical and behavioural changes varies considerably by education and level of concern about global warming.

\section{Discussion}

Based on a nationally representative survey of 3900 adults, the Opinions about the Environment and Global Warming 2010 survey, we found that the key demographic 
Figure 2:

Predicted score with $95 \%$ confidence interval of undertaking technical and behaviour change for a person aged 40-49 years living in the south

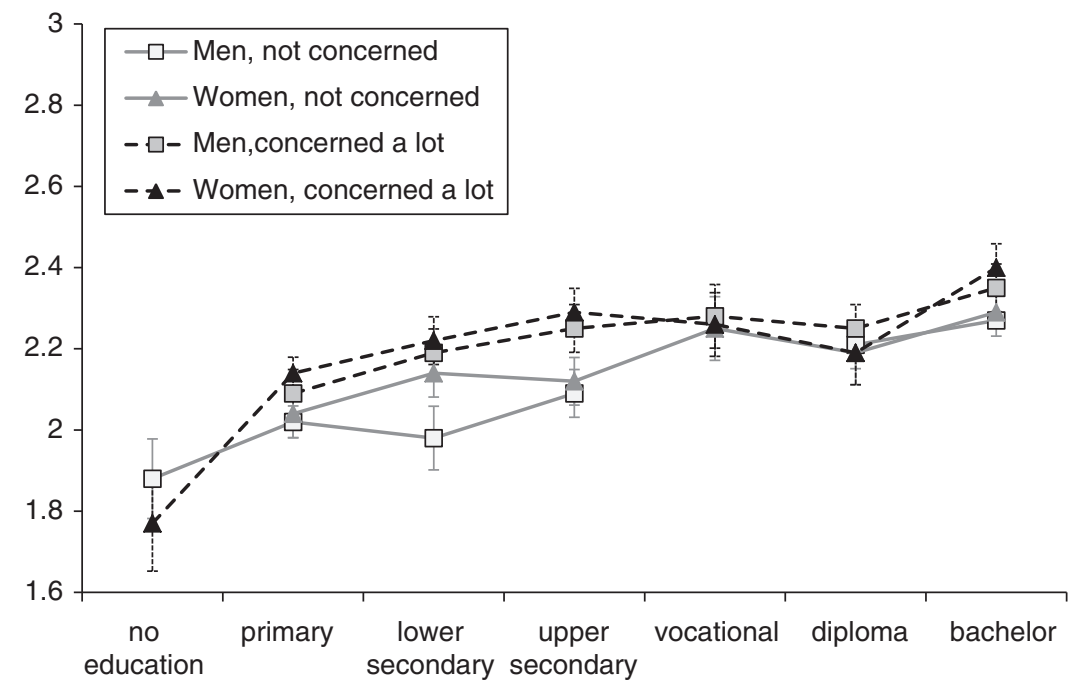

characteristics that explain the level of concern about climate change and the likelihood of adopting behaviours that help to reduce GHG emissions are gender and education. The level of concern about global warming and the likelihood of engaging in mitigation behaviours is thus shown to be greater among women than among men. This finding is consistent with those of previous studies in industrialised countries, such as the United States (McCright and Dunlap 2011a) and Australia (Tranter 2011). After empirically testing different hypotheses regarding the gender differences in levels of climate change concern, McCright (2010) found evidence in support of the gender socialisation argument, which claims that the emphasis on nurture, empathy, and care attached to feminine identity translates into a higher degree of concern about the environment and climate change. Despite their active participation in the economy, the public sector, businesses, and professional occupations, women in Thailand have also been socialised to serve and care for family members and the community (Vichit-Vadakan 2008). Thus, gender socialisation may explain our finding that there are gender differences in levels of concern about climate change and climate-relevant behaviours.

We also found that the level of concern about climate change is greater among individuals with higher levels of education, even when we control for other variables, such as income, that are potentially related to education. More highly educated individuals generally have a better understanding of science and more familiarity with a range of issues than those with less education. Since having 
greater knowledge about climate change has been shown to be positively correlated with concern about climate change (Milfont 2012), it is hardly surprising that we observed a positive relationship between educational attainment and the level of climate change concern. Interestingly, we found no differences by education in the likelihood of taking electricity and water saving actions, but a positive association between education and engaging in actions involving technical and behavioural changes. It is possible that people are more likely to conserve water and electricity because they want to save on the cost of utilities, while they are less likely to make behavioural changes - such as using cloth bags instead of plastic bags, or reducing their use of styrofoam containers-because doing so involves additional effort or decreased comfort. Individuals with higher education, who are generally more concerned about the environment and climate change, may be more willing to perform these actions (Diamantopoulos et al. 2003; Ortega-Egea et al. 2014). Likewise, engaging in technical behaviours such as using energy-saving light bulbs or energy-efficient appliances, requires the individual to have the capacity and desire to accept new information and knowledge (Karytsas and Theodoropoulou 2014; Welsch and Kühling 2010). Our findings therefore suggest that education increases both the level of concern about climate change and the capacity to carry out climatefriendly actions.

The existing literature has found that having a higher income is associated with a greater likelihood of engaging in pro-environmental behaviours, most likely because having a higher income means that an individual's basic material needs have been met, and that he or she can therefore focus on achieving better environmental conditions and a better quality of life (Inglehart 1995). However, we did not find a significant association between income and the level of concern about global warming or pro-environmental behaviours.

The evidence in the literature on the relationship between age and climate change-related attitudes and behaviours is not conclusive (Frederiks et al. 2015). While some previous studies have reported a negative correlation between age and the level of climate change concern (Hamilton 2011; McCright and Dunlap $2011 \mathrm{~b}$ ), and others have found lower levels of concern among the younger and older age groups (Adelekan and Gbadegesin 2005; Agho et al. 2010), we found no significant relationships between these two factors in our Thai sample. Some scholars have argued that the association between the level of environmental concern and demographic characteristics such as age, sex, and race has declined due to the spread of ecological concerns across social groups (Jones and Dunlap 1992). On the other hand, our failure to find an association between age and the level of climate change concern could be attributable to low levels of environmental awareness across age groups in Thailand. Regarding climate-relevant behaviours, it appears that older people are more likely try to conserve electricity and water, but are less likely to engage in technical and behavioural changes. This finding is consistent with the results of a recent study in European countries, which showed that older people are more likely than younger people to be engaged in some form of climate change-motivated activity (Ortega-Egea et al. 2014; Wicker and Becken 
2013). In particular, energy saving behaviour is reported to be positively associated with age (Martinsson et al. 2011; Whitmarsh 2009). Energy consumption is closely related to the life-cycle: i.e. older people tend to consume and travel less than young people. Indeed, for certain climate-relevant behaviours, such as conserving heat and hot water, environmental attitudes play a less important role than socio-demographic factors (Martinsson et al. 2011). Similarly, we find that saving electricity and water is weakly associated with the level of concern about climate change, but is strongly correlated with age. In this case, saving money may be the main incentive, as a previous study found that among households with a high share of elderly members, the most frequently cited reason for conserving energy was financial (Mills and Schleich 2012).

Our finding that people who have experienced environmental problems in their community tend to be more concerned about global warming and more likely to adopt climate-relevant behaviours is in line with the results of previous studies that looked at the impact of having experienced a flood (Spence et al. 2011; Whitmarsh 2008). Experience of natural disasters is easily linked to climate change perception since the likelihood of a risk can be readily imagined. Meanwhile, people who have experienced environmental problems are more likely to report that they are worried about climate change, possibly because they conflate the risks associated with climate change with other environmental risks (Read et al. 1994; Reynolds et al. 2010). Even in European countries, where climate change issues are given more media attention than in less developed countries (Schmidt et al. 2013), people often fail to distinguish between environmental and climate change issues (Fischer et al. 2012). While the conflation of climate change with other environmental problems may hinder the adoption of appropriate behavioural changes and mitigation and adaptation actions (Weber and Stern 2011), in the case of Thailand we found that people who had experienced environmental problems were also more likely to engage in technical and behavioural changes. Promoting accurate knowledge about climate change nevertheless remains crucial, since a lack of knowledge is one of the key barriers to behavioural changes.

Other factors, such as hazard exposure and geographical risk, can also influence an individual's risk perception, and thus his or her level of concern about climate change. Indeed, we found that people who were living in the southern region were less likely to express concern about climate change than those who were living in the central region. In particular, the people who were living in the south were less likely to say they are worried about climate change than those were living in the north, the northeast, or the central regions, where droughts and floods are more frequent (Garbero and Muttarak 2013). While we found no substantial regional differences in the likelihood of conserving electricity and water, people who were living in the northeast were significantly less likely than those living in other parts of the country to report that they had adopted technical and behavioural changes. In the northeast, which is the poorest region in Thailand (Jitsuchon and Richter 2007), there may be contextual factors that constrain pro-environmental behaviour; e.g. a lack of access to a market supply of goods. The northeast also has the lowest average level of 
education in the country, which may hinder the diffusion of knowledge and the acquisition of the skills needed to adopt technical and behaviour changes.

In addition, our analysis clearly shows that engaging in electricity and water saving actions and carrying out technical and behavioural changes are different types of behaviours. The vast majority of the respondents reported that they regularly made efforts to conserve electricity and water. While this behaviour was found to be weakly correlated with concern about global warming, it appears to be mainly motivated by a desire to save money (Whitmarsh 2009). On the other hand, the actions needed to make technical and behavioural changes involve sacrificing comfort and acquiring new appliances. Accordingly, we find that the level of education matters much more for this type of behaviour than for electricity and water conservation actions. While most people pay attention to electricity and water consumption because doing so translates into cheaper electricity and water bills, technical and behavioural change may require certain levels of knowledge and awareness about climate change, and the ability to afford new equipment - attributes that highly educated individuals are more likely to have.

Note that the present study has three main limitations. First, because we were using secondary survey data (i.e. the Opinions about the Environment and Global Warming (OEGW) 2010 data), we relied on how the questions were framed in the survey. In cases in which the respondents had not carried out a particular climaterelevant action, they were given the option of indicating in the same response category either that they had (1) not performed the particular action, or that (2) the question did not apply to them. This could lead to an underestimation of climaterelevant behaviours, since the respondents might have reported that they had not performed a particular action, such as setting an air conditioner to $25^{\circ} \mathrm{C}$, simply because they did not own an air conditioner. To avoid underestimation, we excluded from the statistical analysis these kinds of potentially problematic actions; i.e. setting an air conditioner to $25^{\circ} \mathrm{C}$ and using public transportation.

Second, this study relies on self-reported climate-relevant actions. The respondents may have overstated their levels of concern about climate change and of engagement in mitigation actions due to social desirability biases. If certain demographic groups have a greater tendency to give socially desirable responses instead of choosing responses that represent their true feelings or beliefs, the levels of climate change concern and engagement in mitigation actions estimated will be biased upwards for such groups. It is possible that individuals with higher levels of education tend to over-report their levels of concern about climate change and of engagement in mitigation actions, as has been shown to occur in surveys of voter turnout (Karp and Brockington 2005) or of reading to children (Hofferth 1999). Nevertheless, as our data include non-student samples and the climate-relevant behaviours measured were performed in the past or the present (instead of reflecting future intentions), our measures of climate concern and mitigation actions are unlikely to be affected by social desirability biases (Frick et al. 2004).

Third, our findings may be influenced by the wording of the questions in the survey. Studies in the United States on the extent to which people are concerned 
about climate change have shown that responses varied depending on whether the term 'global warming' or 'climate change' was used (Jang and Hart 2015; Schuldt et al. 2011, 2015). For example, Republican respondents were more likely to have expressed scepticism that global climate change is a real phenomenon when the term 'global warming' rather than 'climate change' was used. However, a survey of 31 countries in Europe revealed that European respondents perceived 'global warming' and 'climate changed' to be equally serious problems (Villar and Krosnick 2010). To our knowledge, there is no such comparative survey for Thailand. It is possible that our finding that $53 \%$ of respondents claim to worry a great deal about global warming is underestimated if Thai citizens follow the US pattern of being more sceptical when the term 'global warming' is used instead of the term 'climate change'. However, we cannot test this possibility with the available data.

\section{Conclusion}

Despite having ratified the Kyoto Protocol in 2002, Thailand continues to experience increasing GHG emissions due to rising energy consumption: in line with the country's rate of economic growth, energy consumption in Thailand has been rising at a rate of 4-5\% per year (APEC 2010). While the power generation, transportation, and manufacturing industrial sectors are major $\mathrm{CO}_{2}$ emitters, household electricity and energy demand has also been rising due to both population growth and economic expansion. It is estimated that if residential consumers switched to high efficiency lighting devices and electrical appliances, as much as 6.53 million tonnes of $\mathrm{CO}_{2}$ emissions could be mitigated in 2020 (Chaosuangaroen and Limmeechokchai 2008). To move towards this goal, the government has implemented several plans and measures designed to promote energy conservation and the use of alternative fuels. Over the past few years, public awareness campaigns have been promoting energy saving and waste reduction measures, such as using fewer plastic bags.

Our study has pointed to the importance of considering demographic differentials in perceptions of climate change and in the accompanying behaviours. As different demographic groups (i.e. men and women, older people and younger people, and the highly educated and the less educated) vary in their life-styles, values, and attitudes; they also differ in their levels of concern and willingness to take action to mitigate climate change. Moreover, there are substantial regional differences in climate-related attitudes and behaviours. Consequently, the psychological, technical, and economic barriers to behavioural change specific to each population sub-group should be considered in GHG emission reduction efforts.

\section{References}

Abrahamse, W., L. Steg, C. Vlek and T. Rothengatter 2005. A review of intervention studies aimed at household energy conservation. Journal of Environmental Psychology 25(3): 273-291. 
Adelekan, I. O. and A. S. Gbadegesin 2005. Analysis of the public perception of climate change issues in an indigenous African city. International Journal of Environmental Studies 62(1): 115-124.

Agho, K., G. Stevens, M. Taylor, M. Barr and B. Raphael 2010. Population risk perceptions of global warming in Australia. Environmental Research 110(8): 756-763.

Alló, M. and M. L. Loureiro 2014. The role of social norms on preferences towards climate change policies: A meta-analysis. Energy Policy 73: 563-574.

APEC 2010. Peer Review on Energy Efficiency in Thailand. Tokyo: Asia Pacific Energy Research Centre (APERC).

Blocker, J. T. and D. L. Eckberg 1997. Gender and environmentalism: Results from the 1993 general social survey. Social Science Quarterly 78(4): 841-858.

Chaosuangaroen, P. and B. Limmeechokchai 2008. Scenario-based assessment of energy savings in Thailand: A long-range energy alternative planning approach. Thammasart International Journal of Science and Technology 13(2): 11-19.

Chotichanathawewong, Q. and N. Thongplew 2012. Development trajectory, emission profile, and policy actions: Thailand, No. 352. Tokyo: Asian Development Bank Institute.

Diamantopoulos, A., B. B. Schlegelmilch, R. R. Sinkovics and G. M. Bohlen 2003. Can sociodemographics still play a role in profiling green consumers? A review of the evidence and an empirical investigation. Journal of Business Research 56(6): 465-480.

Diekmann, A. and P. Preisendörfer 2003. Green and greenback the behavioral effects of environmental attitudes in low-cost and high-cost situations. Rationality and Society 15(4): $441-472$.

Dietz, T., G. T. Gardner, J. Gilligan, P. C. Stern and M. P. Vandenbergh 2009. Household actions can provide a behavioral wedge to rapidly reduce US carbon emissions. Proceedings of the National Academy of Sciences 106(44): 18452-18456.

Dunlap, R. E. and R. York 2008. The globalization of environmental concern and the limits of the postmaterialist values explanation: Evidence from four multinational surveys. Sociological Quarterly 49(3): 529-563.

EEPO 2011. Thailand 20-Year Energy Efficiency Development Plan 2011-2030 (EEDP). Bangkok, Thailand: Energy Policy and Planning Office, Ministry of Energy. http://www.eppo.go.th/encon/ee-20yrs/EEDP_Eng.pdf.

Egan, P. J. and M. Mullin 2012. Turning personal experience into political attitudes: The effect of local weather on Americans' perceptions about global warming. The Journal of Politics 74(3): 796-809.

Fischer, A., V. Peters, M. Neebe, J. Vávra, A. Kriel, M. Lapka and B. Megyesi 2012. Climate change? No, wise resource use is the issue: Social representations of energy, climate change and the future. Environmental Policy and Governance 22(3): 161-176.

Frederiks, E. R., K. Stenner and E. V. Hobman 2015. Household energy use: Applying behavioural economics to understand consumer decision-making and behaviour. Renewable and Sustainable Energy Reviews 41: 1385-1394.

Frick, J., F. G. Kaiser and M. Wilson 2004. Environmental knowledge and conservation behavior: Exploring prevalence and structure in a representative sample. Personality and Individual Differences 37(8): 1597-1613. 
Gamberini, L., A. Spagnolli, N. Corradi, G. Sartori, V. Ghirardi and G. Jacucci 2014. Combining implicit and explicit techniques to reveal social desirability bias in electricity conservation self-reports. Energy Efficiency 7(6): 923-935.

Garbero, A. and R. Muttarak 2013. Impacts of the 2010 droughts and floods on community welfare in rural Thailand: Differential effects of village educational attainment. Ecology $\mathcal{F}$ Society 18(4): 27.

Gardner, G. T. and P. C. Stern 2002. Environmental Problems and Human Behavior. Boston: Pearson.

Gardner, G. T. and P. C. Stern 2008. The short list: The most effective actions U.S. households can take to curb climate change. Environment: Science and Policy for Sustainable Development 50(5): 12-25.

Gelissen, J. 2007. Explaining popular support for environmental protection a multilevel analysis of 50 nations. Environment and Behavior 39(3): 392-415.

Hamilton, L. C. 2011. Education, politics and opinions about climate change evidence for interaction effects. Climatic Change 104(2): 231-242.

Hamilton, L. C. and M. D. Stampone 2013. Blowin' in the wind: Short-term weather and belief in anthropogenic climate change. Weather, Climate, and Society 5(2): 112-119.

Hofferth, S. L. 1999. Family reading to young children: Social desirability and cultural biases in reporting. Presented at the Workshop on the Measurement of and Research on Time Use, National Research Council, Committee on National Statistics.

Howell, S. E. and S. B. Laska 1992. The changing face of the environmental coalition a research note. Environment and Behavior 24(1): 134-144.

IEA 2010. World Energy Statistics 2010. Paris: International Energy Agency. http://www.iea.org/countries/

Inglehart, R. 1995. Public support for environmental protection: Objective problems and subjective values in 43 societies. PS: Political Science $\mathcal{E}$ Politics 28(01): 57-72.

Jang, S. M. and P. S. Hart 2015. Polarized frames on "climate change" and "global warming" across countries and states: Evidence from twitter big data. Global Environmental Change 32: 11-17.

Jitsuchon, S. and K. Richter 2007. Thiland's poverty maps: From construction to application. In More than a Pretty Picture: Using Poverty Maps to Design Better Policies and Interventions, eds T. Bedi, A. Coudouel and S. Kenneth, 241-260. Washington, DC: World Bank Publications.

Joireman, J. and R. Liu 2014. Future-oriented women will pay to reduce global warming: Mediation via political orientation, environmental values, and belief in global warming. Journal of Environmental Psychology.

Jones, R. E. and R. E. Dunlap 1992. The social bases of environmental concern: Have they changed over time? Rural Sociology 57(1): 28-47.

Karp, J. A. and D. Brockington 2005. Social desirability and response validity: A comparative analysis of overreporting voter turnout in five countries. Journal of Politics 67(3): 825840.

Karytsas, S. and H. Theodoropoulou 2014. Socioeconomic and demographic factors that influence publics' awareness on the different forms of renewable energy sources. Renewable Energy 71: 480-485. 
Kellstedt, P. M., S. Zahran and A. Vedlitz 2008. Personal efficacy, the information environment, and attitudes toward global warming and climate change in the United States. Risk Analysis 28(1): 113-126.

Liere, K. D. V. and R. E. Dunlap 1980. The social bases of environmental concern: A review of hypotheses, explanations and empirical evidence. Public Opinion Quarterly 44(2): 181-197.

Li, Y., E. J. Johnson and L. Zaval 2011. Local warming daily temperature change influences belief in global warming. Psychological Science 22(4): 454-459.

Lorenzoni, I. and N. F. Pidgeon 2006. Public views on climate change: European and USA perspectives. Climatic Change 77(1-2): 73-95.

Malka, A., J. A. Krosnick and G. Langer 2009. The association of knowledge with concern about global warming: Trusted information sources shape public thinking. Risk Analysis 29(5): 633-647.

Martinsson, J., L. J. Lundqvist and A. Sundström 2011. Energy saving in Swedish households. The (relative) importance of environmental attitudes. Energy Policy 39(9): 5182-5191.

McCright, A. M. 2010. The effects of gender on climate change knowledge and concern in the American public. Population and Environment 32(1): 66-87.

McCright, A. M. and R. E. Dunlap 2011a. Cool dudes: The denial of climate change among conservative white males in the United States. Global Environmental Change 21(4): 1163-1172.

McCright, A. M. and R. E. Dunlap 2011b. The politicization of climate change and polarization in the American public's views of global warming, 2001-2010. Sociological Quarterly 52(2): 155-194.

McGregor, J. A. 2008. Wellbeing, development and social change in Thailand. Thammasat Economic Journal 26(2): 1-27.

Milfont, T. L. 2012. the interplay between knowledge, perceived efficacy, and concern about global warming and climate change: A one-year longitudinal study. Risk Analysis 32(6): 1003-1020.

Mills, B. and J. Schleich 2012. Residential energy-efficient technology adoption, energy conservation, knowledge, and attitudes: An analysis of European countries. Energy Policy 49: 616-628.

Ortega-Egea, J. M., N. García-de-Frutos and R. Antolín-López 2014. Why do some people do "more" to mitigate climate change than others? Exploring heterogeneity in psycho-social associations. PLOS ONE 9(9): e106645.

Pacala, S. and R. Socolow 2004. Stabilization wedges: Solving the climate problem for the next 50 years with current technologies. Science 305(5686): 968-972.

Poortinga, W., L. Steg, C. Vlek and G. Wiersma 2003. Household preferences for energysaving measures: A conjoint analysis. Journal of Economic Psychology 24(1): 49-64.

Read, D., A. Bostrom, M. G. Morgan, B. Fischhoff and T. Smuts 1994. What do people know about global climate change? Survey studies of educated laypeople. Risk Analysis 14(6): 971-982. 
Reynolds, T. W., A. Bostrom, D. Read and M. G. Morgan 2010. Now what do people know about global climate change? Survey studies of educated laypeople. Risk Analysis 30(10): $1520-1538$.

Romani, M., J. Rydge and N. Stern 2012. Recklessly slow or a rapid transition to a low-carbon economy? Time to decide. London: Grantham Research Institute on Climate Change and the Environment. http://www.lse.ac.uk/GranthamInstitute/publication/ recklessly-slow-or-a-rapid-transition-to-a-low-carbon-economy-time-to-decide/, accessed on 22 October 2014.

Running, K. 2013. World citizenship and concern for global warming: Building the case for a strong international civil society. Social Forces 92(1): 377-399.

Sadorsky, P. 2014. The effect of urbanization on CO2 emissions in emerging economies. Energy Economics 41: 147-153.

Schmidt, A., A. Ivanova and M. S. Schäfer 2013. Media attention for climate change around the world: A comparative analysis of newspaper coverage in 27 countries. Global Environmental Change 23(5): 1233-1248.

Schuldt, J. P., S. H. Konrath and N. Schwarz 2011. "Global warming" or "climate change"? Whether the planet is warming depends on question wording. Public Opinion Quarterly 75(1): 115-124.

Schuldt, J. P., S. Roh and N. Schwarz 2015. Questionnaire design effects in climate change surveys implications for the partisan divide. The ANNALS of the American Academy of Political and Social Science 658(1): 67-85.

Semenza, J. C., D. E. Hall, D. J. Wilson, B. D. Bontempo, D. J. Sailor and L. A. George 2008. Public perception of climate change: Voluntary mitigation and barriers to behavior change. American Journal of Preventive Medicine 35(5): 479-487.

Shrestha, R. M. and S. Pradhan 2010. Co-benefits of CO2 emission reduction in a developing country. Energy Policy 38(5): 2586-2597.

Spence, A., W. Poortinga, C. Butler and N. F. Pidgeon 2011. Perceptions of climate change and willingness to save energy related to flood experience. Nature Climate Change 1(1): 46-49.

Spence, A., W. Poortinga and N. Pidgeon 2012. The psychological distance of climate change. Risk Analysis 32(6): 957-972.

Stern, P. C., L. Kalof, T. Dietz and G. A. Guagnano 1995. Values, beliefs, and proenvironmental action: Attitude formation toward emergent attitude objects. Journal of Applied Social Psychology 25(18): 1611-1636.

Swim, J., S. Clayton, T. Doherty, R. Gifford, G. Howard, J. Reser, et al 2009. Psychology and global climate change: Addressing a mutifaceted phenomenon and set of challenges. Washington, DC: American Psychological Association. http://digital.library.unt.edu/ark: /67531/metadc28583/, accessed on 29 October 2014.

Taylor, A., W. B. de Bruin and S. Dessai 2014. Climate change beliefs and perceptions of weather-related changes in the United Kingdom. Risk Analysis 34(11): 1995-2004.

Tjernström, E. and T. Tietenberg 2008. Do differences in attitudes explain differences in national climate change policies? Ecological Economics 65(2): 315-324. 
Tobler, C., V. H. M. Visschers and M. Siegrist 2012. Addressing climate change: Determinants of consumers' willingness to act and to support policy measures. Journal of Environmental Psychology 32(3): 197-207.

Tranter, B. 2011. Political divisions over climate change and environmental issues in Australia. Environmental Politics 20(1): 78-96.

Vichit-Vadakan, J. 2008. Women in politics and women and politics: A socio-cultural analysis of the Thai context. In Women and politics in Thailand: Continuity and change, ed. K. Iwanaga, 27-53. Copenhagen: NIAS Press.

Villar, A. and J. A. Krosnick 2010. Global warming vs. climate change, taxes vs. prices: Does word choice matter? Climatic Change 105(1-2): 1-12.

Weber, E. U. and C. K. Hsee 1999. Models and mosaics: Investigating cross-cultural differences in risk perception and risk preference. Psychonomic Bulletin $\mathcal{G}$ Review 6(4): 611-617.

Weber, E. U. and P. C. Stern 2011. Public understanding of climate change in the United States. American Psychologist 66(4): 315-328.

Welsch, H. and J. Kühling 2010. Pro-environmental behavior and rational consumer choice: Evidence from surveys of life satisfaction. Journal of Economic Psychology 31(3): 405-420.

Whitmarsh, L. 2008. Are flood victims more concerned about climate change than other people? The role of direct experience in risk perception and behavioural response. Journal of Risk Research 11(3): 351-374.

Whitmarsh, L. 2009. Behavioural responses to climate change: Asymmetry of intentions and impacts. Journal of Environmental Psychology 29(1): 13-23.

Whitmarsh, L. 2011. Scepticism and uncertainty about climate change: Dimensions, determinants and change over time. Global Environmental Change 21(2): 690-700.

Wicker, P. and S. Becken 2013. Conscientious vs. ambivalent consumers: Do concerns about energy availability and climate change influence consumer behaviour? Ecological Economics 88: 41-48.

Wolfe, R. and W. Gould 1998. An approximate likelihood-ratio test for ordinal response models. Stata Technical Bulletin 7(42): 24-27.

Wood, B. D. and A. Vedlitz 2007. Issue definition, information processing, and the politics of global warming. American Journal of Political Science 51(3): 552-568.

Zelezny, L. C., P.-P. Chua and C. Aldrich 2000. New ways of thinking about environmentalism: Elaborating on gender differences in environmentalism. Journal of Social Issues 56(3): 443-457. 